\title{
The Virtue of Patience
}

\author{
Scott Grills \\ Brandon University, Canada
}

DOI: http://dx.doi.org/10.18778/1733-8077.16.2.03

\section{Keywords:}

Fieldwork; Methods;

Symbolic Interaction;

Patience; Ethnography

\begin{abstract}
Shaffir (1998:63) writes, “We must learn to reclaim the virtue of patience. When we enhance the pace of doing research, it is often at the expense of acquiring a deep appreciation of the research problem." This paper engages Shaffir's claim by examining the importance of undertaking a patient sociology. What is the virtue to be found in prolonged and sustained work? How does this speak to the relationships found in field research and in the identities that inform our work as researchers and theorists? In contrast to recent trends towards various versions of instant or shortterm ethnography (e.g., Pink and Morgan 2013) this paper argues for the merits of "slow" ethnography by examining the advantages of relational patience, perspectival patience, and the patience required to fully appreciate omissions, rarities, and secrets of the group.
\end{abstract}

Scott Grills is a Professor of Sociology at Brandon University, Manitoba, Canada. He is the co-author of Management Motifs: An Interactionist Approach for the Study of Organizational Interchange (2019) and co-editor of Kleine Geheimnisse: Alltagssoziologische Einsichten [Little Secrets: Everyday Sociological Insights] (2015). He served as the President of the Society for the Study of Symbolic Interaction in 2010/11 and as Vice-President in 2007/08. Earlier publications include those in the areas of interactionist theory, deviant behavior, the sociology of music, political processes, and the sociology of doubt. His current ethnographic research attends to management processes and the entrepreneurial activities of new Canadians.

email address: grillss@brandonu.ca

\section{A Personal Introduction}

It is a genuine pleasure to contribute this paper to a festschrift marking the contributions of William Shaffir. I began my doctoral studies at McMaster University, and wrote my dissertation under Shaffir's mentorship and guidance (Grills 1989). The doctoral program at McMaster in the 1980's sustained a local culture that supported students working within the interactionist tradition. I had a vague generalized notion of what I thought I wanted to do (in my case, I was interested in trying to extend labeling theory by attending more explicitly to the championing of deviance designations) and a methodological commitment to ethnographic research 
methods. I was at McMaster during what was the "golden moment" for interactionist work there. In addition to Shaffir, faculty members included Jack Haas (one of Shaffir's co-authors), Richard (Dick) Brymer, Ralph Matthews, Peter Archibald, Charlene Miall, and Dorothy Pawluch. This combination of interactionist scholars and interactionist-friendly scholars allowed for a unique concentration of interpretive work to occur in one place at one time. ${ }^{1}$ This was an engaging time for interactionist scholarship in Canada, and Shaffir was a central part of this and an integral part of my mentorship into this community of scholars.

While McMaster was a center for interactionist thought in Canada, Shaffir was also a part of a network of Canadian interactionist scholars that included rather centrally Robert Prus (University of Waterloo), Mary Lou Dietz (University of Windsor), Robert Stebbins (University of Calgary), and Nancy Mandell (York University). These scholars were instrumental in creating and sustaining what was to become the annual Qualitative Analysis Conference, held initially in 1984 at the University of Waterloo and co-sponsored by McMaster University and the Social Sciences and Humanities Research Council of Can$a d a$. These meetings have run consecutively now for 35 years.

The first published volume to come out of these meetings was 1994's Doing Everyday Life edited by Dietz, Prus, and Shaffir. The second volume based on the conference was my own edited book from 1998, Doing Ethnographic Research. Shaffir's contribution to that volume was his essay "Research in Jewish Orthodox Communities: The Neglected Role

${ }^{1}$ For a discussion of symbolic interaction in Canada see HelmesHayes and Milne (2017), Low (2017), and McLuhan and Puddephatt (2017). of Sociability."2 That essay draws upon Shaffir's extended body of research with Jewish communitiesfrom his book Life in a Religious Community (1974) to his essay Still Separated from the Mainstream: Life in a Hassidic Community (1997). However, the importance of Shaffir's (1998) discussion of sociability is to be found in its attention to central aspects of ethnographic research such as locating respondents, gaining access, examining how subjects understand the objectives of the research, and exploring how subjects' perceptions of the researcher influence the project at hand. Shaffir (1998:63) concludes by asserting that:

We must reclaim the virtue of patience. When we enhance the pace of doing research, it is often at the expense of acquiring a deep appreciation of the research problem. As we sacrifice quality for quantity, we short-change not only those persons whose perspective we seek to understand, but also an approach to studying social life that holds the greatest promise for acquiring the most credible understanding of the dynamics of social interaction.

There is an implicit ethical stance articulated here, for this position speaks directly to the researcher/ respondent relationship and the need to avoid privileging the interests of the researcher and thereby "short-changing" the other. As such, researchers are encouraged to attend to the central themes of genuinely hearing participants, listening to their words, attending respectfully to meaning, and becoming accustomed to the rhythms of their lives. Patiencesincere patience-nurtures genuine relations in the field. This paper takes up the spirit of Shaffir's

\footnotetext{
${ }^{2}$ Other volumes that include Shaffir's work and are developed, at least in part, from the Qualitative Analysis meetings include Pawluch, Shaffir, and Miall (2005), Puddephatt, Shaffir, and Kleinknecht (2009), Low and Bowden (2013) and Kleinknecht, van den Scott, and Sanders (2018).
} 
(1998) position and attempts to extend his argument for the "virtue of patience." Specifically, I examine the merits of "slow" ethnography by exploring the methodological importance of relational patience, perspectival patience, and the patience required to fully appreciate omissions, rarities, and secrets of the group.

\section{Relational Patience}

Relational patience is a virtue for the researcher who seeks to occupy the place of the ethnographic other. Shaffir (e.g., 1999) has written broadly in the area of field methods and ethnographic research. A theme that connects this work is the shared emphasis on relationships in field settings-on how researchers form particularistic bonds with others and how those bonds locate the researcher in a community context. Central to this is a serious attentiveness to how participants in settings view the researcher. While getting in to a setting, learning the ropes, developing a sense of routines, and knowing when to write a project up are all key aspects of any research project and process, Shaffir (1998) suggests that the success of any field work project depends less on the research bargain, the purpose of the research, or the organizational requirement of informed consent, than it does on peoples' perception of the researcher as an "ordinary human being who respects them, is kindly disposed towards them and is willing to conform to their code of behavior when he or she is with them" (Shaffir 1990:80). Shaffir (1990) discusses the importance of being defined as a mensch-a decent person with a sense of humor, a willingness to share, and someone who engenders the trust of others. While analytically distinct, the dual themes of reputations and identities are co-present here. Reputational integrity in the field requires maintaining a convincing presentation of self.
Shaffir's position assumes something rather important; it assumes that there are research relationships. And it is posited that these relationships are meaningful ones-the kind that take time to build up, where the researcher is known as a person to those whose particular lives they seek to understand, where the researcher spends time in a setting where they are welcomed in and invited back, where, possibly, they are thought kindly of. These are relationships where researchers are challenged from time to time, embraced, and when absent may be missed. The research relationship is distinct from other dynamics in the field. For example, unobtrusive measures eschew a research relationship entirely. We can examine the number of nose-prints on the glass of a museum exhibit to gain a sense of the frequency of views of the exhibit, and examine their height to extrapolate age, but the research posture taken is intentionally non-relational (Webb et al. 1999).

While research encounters are joint acts in the full sense of the term (Couch 1984), nevertheless they are research exchanges marked by a more fleeting and instrumentally defined relationship. The researcher seeks "data" and the informant is of "value" in the research encounter relative to the information to be derived. Research encounters may be quite beneficial for some forms of social science research. A national census relies on such encounters as does rather crucial research on the immediate needs of persons displaced by natural disasters, or the demand for accessibility services for students transitioning from high school to university. While these research encounters may be precarious in various ways and they may fail to achieve their research objectives given attributions made by respondents (e.g., the encounter may be defined as deceptive, unsafe, too time consuming, or unwelcome in a variety of ways), the emphasis is placed on the encounter 
as a means to accomplish an often clearly defined research end.

In contrast, research relationships, as used herein, denote the identity-rich and multi-faceted aspects of the particularistic bonds formed in the field. Research relationships are pursued and sustained where researchers have an interest in learning the ways of the subculture. Here researchers fully engage people's activities, perspectives, argot, and the various norms, folkways, and social boundaries of everyday life. By so doing, researchers come to appreciate the limits of humor, the socially constructed realities that sustain subcultural versions of "truth" and the worries, doubts, and uncertainties of the group. Researchers learn what is of subcultural value and how that value is sustained and maintained. In many ways deep, meaningful research relationships are a rather central aspect of achieving Blumer's (1969) elusive intimate familiarity of the social world.

Sharing some qualities with Schütz' (1944) framing of the stranger, the ethnographer as other occupies a place of some distance from those who are fully "in" and "of" the subcultural setting. Even where ethnographers are full members of the research site, their interests, questions, and concepts alter the relational dynamic in the field. While researchers may themselves be exotic dancers (Colosi 2010) or card hustlers (Prus and Sharper 1991), ethnographic relations alter prior relationships-as researchers become subcultural members who are "writing about us" and may become "our sociologist." Quite apart from how researchers may frame their own identities (e.g., as Wolf [1991] has suggested; he was a biker first and an anthropologist second), relationships in the field are modified by and through the reputations established by researchers in the field. These relationships, like the other more enduring bonds that people establish with one another, require time and patience to develop. There is no substitute for this. To be present, over weeks, over months, and over years allows those whose lives researchers seek to understand a chance to observe our commitment to the field, our openness to the ways of the people, our willingness to be made uncomfortable, be inconvenienced, share emotions, and to be tested and not found wanting.

\section{Perspectival Patience}

As Prus (1996) has argued, human group life is, in part, perspectival. The inter-subjective world of everyday life is realized through the meaning-based actions of people as they go about their everyday lives. The world of everyday life is our point of departure and our point of return with respect to the finite provinces of meaning that we encounter. Everyday life is the world we return to after giving ourselves over to the emotive experience of religious ritual, the passion of a lover's embrace, or the recreational terror of the horror film. It is within the world of the everyday that the realities of our lives reside. ${ }^{3}$ The simple elegance of Blumer's (1969) assertion that people act towards the world of everyday life on the basis of the meaning it holds for them masks the methodological complexity of learning the perspectives of others. But, that is what is required if a deep and intimate familiarity with the world of the other is to be achieved (Lofland 1976:812). For researchers, patience in the field is required if a genuine appreciation of the complexity of the various worldviews, understandings, concepts, and perceptions invoked in any particular setting are to be fully understood.

${ }^{3}$ This framing is indebted to Schütz $(1962 ; 1964)$ and Berger and Luckmann (1966). 
As Shaffir's body of work pertaining to Orthodox Jewish experiences illustrates, not only may the worldviews that people hold be complex in their own right, participants may also face considerable challenges to perspectives held from those within their own community of adherents and from those who find the perspectives of subcultural members unwelcome, distancing, or otherwise troubling. For researchers, there is little in the way of a substitute for taking the time and putting in the work necessary to fully comprehend the worldviews at hand in any subcultural setting. Without a strong rapport with informants, it is challenging, indeed, for researchers to fully appreciate the nuances of perspective and meaning in play. Spradely's (2000) research with urban nomads is a helpful example here. By gaining the confidence of street affected persons, Spradely's work offers a ground-breaking rendering of the various understandings that people who may be formally identified as "unemployed" define work and working and the practical strategies associated with "making it" on the street. ${ }^{4}$

Drawing on various prior experiences, participants may experience significant misgivings, uncertainties, and cautions with respect to sharing their worldviews with others. It takes considerable rapport between informants and researchers for the various cloaks of competence that may cast shadows over the rituals of impression management to be seen, thereby allowing for a more detailed, forthcoming, and nuanced sharing of worldviews (Haas and Shaffir 1987). While no amount of time in the field may be adequate to overcome the misgivings of some, one of the virtues of patience is the oppor-

\footnotetext{
${ }^{4}$ For example, Spradely (2000) examines alternate forms of economic activities undertaken by urban nomads such as donating blood, obtaining resources from secondary aid agencies ("making the Sally"), and identifying appropriate targets for resources ("finding a live one").
}

tunity for researchers to more fully appreciate how participants come to understand the world as they do-to comprehend the everyday knowledge that is applied to situations at hand.

Without taking the time to learn the various worldviews within a subculture, researchers run the risk of discounting or diminishing the importance of people's worldviews to strong ethnographic research. If people act on the basis of meaning, then we have to do the work to understand those meaning sets if we are to understand the joint action that accompanies them. However, in the absence of time in the field and the full engagement with participant perspectives, one of the tendencies is for researcher perspectives to dominate the analysis and to restrict (if not sideline entirely) participants' voices. And when that happens, there is a distorting effect as the participants are written out of their own accounts in favor of the various agendas of the researcher. ${ }^{5}$

This can happen in a variety of ways, but three are particularly relevant to the ethnographic tradition in a contemporary context. Firstly, researchers may prioritize their own experiences in the field over the perspectives of participants. Here the members of the subculture at hand are not the "stars of the show," but rather are cast in secondary roles in favor of a detailed discussion of how difficult, traumatizing, and/or emotively draining the project was for the researcher.

Secondly, researchers may abandon an understanding of participants' perspectives in favor of

\footnotetext{
${ }^{5}$ Through various activities the research encounter may share some qualities with dominance and subjugation more generally (Athens 2015a). See Grills (2018) for a discussion of these themes.
} 
embracing the opportunity to apply deviance designations to particular notions at hand. Here the designation of particular worldviews as somehow morally unacceptable replaces the pursuit of verstehen. We learn what the researcher finds offensive and what labels they are inclined to apply, but we learn little about the worldviews of participants or their lives, except as filtered through the lens of researcher as moral entrepreneur (Becker 1963).

Thirdly, researchers may impute meaning based upon their own prior conceptualizations and typifications. For example, where researchers are drawing upon observational data of joint acts and, at the same time, have limited access to the definitions of the situation of participants, the interpretation of these acts rests more exclusively on the perspectives of the researcher, not the participants. When this occurs, meaning may be rendered non-problematic, and while this may facilitate analysis, it is an oversimplification of the empirical world. The study of interpersonal violence is illustrative here. In contrast to dedicated field research, it is most certainly easier for researchers to distance themselves from interpersonal violence, to study representations of violence in the media, to attribute meaning to violence displays in professional sport, and to participate in denouncing violence and contribute to moral panics concerning violence. However, if we are to understand violence in everyday life, then we need to attend to the meaning sets that contribute to the construction of violence as an available interactional resource and the accompanying social processes of brutalization and violentization (Athens 2015b).

When researchers fail to grasp the worldviews at hand, their analysis is inevitably marked by a somewhat distorted understanding of the sub- cultural setting. Colosi (2010:7) describes her experience of encountering an outside researcher's representations of exotic dancing, "It was my experience of working as a dancer that alerted me to the lack of understanding of and the many myths surrounding the industry. It was apparent that those attempting to tell my story and the stories of all my fellow dancers were outsiders, albeit strangers to our world." While researchers may not pursue "insider" status, one of the virtues of patience in the field is the ability to develop a complex and rich understanding of the perspectives of those in the setting.

An additional virtue of perspectival patience for field researchers is to be found in the development of perspectival fluency over time. Gubrium's (1991) attentiveness to local cultures and changes over time is instructive here. Gubrium found that the concept of "emotional disturbance" employed by clinicians in a juvenile detention center was an organizing principle for behavioral modification strategies employed by staff, but was virtually absent from the facility during weekends. The everyday reality that full-time clinical staff members were not present in the field site on weekends meant that the organizing perspectives in the setting changed. The ways in which youth behaviors were defined by the "weekenders" tended to reflect the perspectives of those who came from backgrounds more closely aligned to childcare traditions. Youth in custodial care routinely altered their behavior to attend to the distinction between weekday and weekend expectations. There is an important lesson in perspectival patience here. Not only does the acquisition of perspectival fluency require time in the field, it also requires being attentive to how perspectives may vary temporally-over the subculturally situated 
rhythms of the day, the week, or from season to season. ${ }^{6}$

The various worldviews, realities, meaning sets, and typifications that are to be found in any particular subcultural setting may be challenging for researchers to take into account. Even where researchers may have higher levels of familiarity of the setting at hand, the concerted and direct efforts to develop more complete and comprehensive understandings of the full range of perspectives nevertheless require considerable time and presence. As Shaffir (1999:684-685) has argued, "the most creditable understanding of social phenomena requires the researcher to discover the actors definition of the situation...and that such discovery is best accomplished by placing oneself in the other person's situation."

\section{Patience and Voids}

Advisory texts for those first entering the field note the importance of capturing aspects of the settings as they present themselves to researchers. Novice researchers may be encouraged to attend to the words used by informants, focus on what is occurring in the setting, be encouraged to avoid capturing only what researchers consider important, and to limit conjecture. This is sound, practical advice to be sure. In this we see the starting point of classic ethnography-hang around, see what is happening, listen, and observe. These activities allow researchers to attend to everyday life as it unfolds within the setting. But, what of what is not done, not spoken, those lines of action not taken-

\footnotetext{
${ }^{6}$ For a discussion of the importance of multi-contextuality in generating what constitutes sociological "evidence" see Zerubavel (2007) and Becker (2017).
}

the negative spaces in field research? That is much more of a challenge to attend to. ${ }^{7}$

I would suggest that one of the virtues of patience in the field is found in the opportunities afforded to researchers to fully comprehend voids-the nothings-in the setting at hand. The roads not taken may be as analytically and sociologically relevant as activities and missions more directly engaged and undertaken. As Scott (2018:1) argues, "Nothing is a sociologically neglected terrain, comprising negatively defined phenomena, such as non-identification, non-participation, and non-presence. Nevertheless, these symbolic social objects are created and managed through meaningful social interaction." For example, Grills and Prus (2019) have examined the self in the context of experiencing management, being managed, and self-management. A rather central theme in this analysis is an examination of how those who hold offices may come to define inaction, delay, or doing nothing as a viable (if not at times preferred) course of (in)action. Managers may opt for inaction out of: (1) a lack of perceived strategic interest, (2) identity and reputational concerns, (3) resistance strategies, (4) distancing strategies, (5) competencies and skills-based concerns, (6) managing uncertainties, and (7) competing commitments and obligations (Grills and Prus 2019:185-186). ${ }^{8}$ Obtaining an intimate familiarity with what is not done, an appreciation of not doing as strategic action, and the importance of office holders acquiring definitions of the situation that attend to the merits of inaction are rather central to understanding management in everyday life.

\footnotetext{
${ }^{7}$ Hillyard's (2019) paper “The Rising Salience of the Absent: An Interactionist Analysis" offers a helpful commentary on this theme.

${ }^{8}$ For a more complete discussion of these themes see Chapter 8 of Grills and Prus' (2019) Management Motifs.
} 
However, as a methodological matter, it takes considerable closeness to a setting to understand what is unseen. For example, a substantial depth of understanding of a setting is required to be in a position to attend to the voids created by failed messianic prophecy (Shaffir 1995). Researchers are encouraged to attend to some of the multiple ways that absence, voids, and null spaces may be a useful analytical resource in field research. Researchers approach subcultural settings with a variety of prior constructs, understandings, personal experiences, and generalized anticipatory notions. It cannot be otherwise. Even where the ethnographer is entering relatively unfamiliar settings, an understanding of generic social processes may provide initial conceptual frameworks from which we may attend to self/other identities, joint acts, acquiring perspectives, and the relational dynamics to be found in any particular setting. ${ }^{9}$ At times, however, anticipated aspects of human group life may be less readily available for researchers to encounter or engage.

Brymer's (1998) work on gangs and gangsters is instructive here. Brymer spent seven years studying Mexican-American conflict gangs. As he notes, he routinely spent time in the field with "gang guys." These are individuals with gang affiliations, who interacted with each other on the basis of small friendship cliques of 8-10 members, referred to as palomillas. While local discourse made reference to gangs, everyday interactions centered on these smaller group relationships. Brymer notes that it took more than two years of field research before circumstances arose wherein gang members came together to create a symbolic and actual move from palomillas members

${ }^{9}$ Readers interested in attending more fully to generic social processes and the symbolic interactionist tradition are directed to Blumer (1969), Lofland (1976), Couch (1984), Wiseman (1987), Prus (1996), and Puddephatt and McLuhan (2019). to armed, potentially deadly gang members. Reflecting on the methodological implications of attending to this transition, Brymer (1998:148-149) writes,

So what does this tell us about field research?...Certain events such as gang fights are rare and exceptional events, as a researcher you may have to hang around for a long time before you can "see" them...[Such] exceptional events may be the missing piece in the puzzle, be patient.

Relatedly, we may also attend to the secrets of the group - that which is not present, not visible, and not available. These absences relate to the audience specific work of not saying, not revealing, and of concealment, and potential misdirection. Simmel (1906) framed the secret in sociological terms-attending to the secret as a more generic feature of social life. Simmel draws our attention to the power of the secret and how that power, such as it is, is realized only in the telling. But, by so doing, the power held by knowing the secret is lost in the telling, though the revelation of the secret may bring with it the ability to inflict certain harms or lay claim to the identity of a secret holder. Both Becker (1963) and Goffman (1959; 1963) attend to secrecy in the context of deviance and identity. The difference between the discredited and the discreditable may rest on the secret kept-the null space in the interaction sequence.

For Mitchell (1991), in field research it is rather essential to understand the secrets of the group. He draws out the helpful distinction between the egocentric secret and the ethnocentric secret. Egocentric secrets are aspects of peoples' identities and relationships that participants may seek to shield from various audiences. For example, participants in an environmental movement may conceal their potentially discrediting employment in the oil industry, members of the clergy 
may conceal doubts and uncertainties about the nature of the divine, and those seeking public office may attempt to conceal prior illicit involvements. Ethnocentric secrets are secrets of the group, that were revealed, are perceived to place the group in some form of risk or consequences defined as unwelcome in a variety of ways. For field researchers who seek to occupy the position of full participant observer, learning the secrets of the group is essential to understand the subcultural setting. As Grills and Prus (2019:147) note, "access to the secrets of the team may rather centrally distinguish those who are 'full team members' from those more peripheral to the enterprise."

One of the challenging aspects of field research is the problem of absences, voids, and that which is not present and/or not perceived. It can be difficult to differentiate between absence (that which is not present in a subcultural setting), omission (that which is a potential and available line of action that is untaken), secrecy (that which is concealed from the perception of the observer), and that which is unseen due to the everyday reality that the aspect of social life it reflects is a rare and/or isolated occurrence (as understood relative to the subculture at hand). For researchers who are committed to getting to where the action is and observing human group life, it is not enough to rely on cultural narrative (and mythologies) about gangs, or cults, or epiphanies of persons. The goal is to observe people as they undertake these various activities, to attend to the practical accomplishment of these aspects of everyday life, and to link or ground conception via perception (Blumer 1969). ${ }^{10}$

Therefore, one rather important virtue of patience in ethnographic research is that over time researchers

\footnotetext{
${ }^{10}$ Readers are specifically directed to the chapter Science without Concepts (Blumer 1969:153-170).
}

may, with greater levels of assurance, be able to differentiate between absence, omission, secrecy, and rarity. By so doing, the "no things" that are parts of the research process are more fully understood through time in the research setting. Simply put, there is no adequate substitute for patience in the field if we are to observe and engage the everyday voids that are a part of human group life.

\section{In Sum}

There is no substitute for time in the field. But, time alone does not build research relationships. Shaffir has stressed throughout his teaching and writing the centrality of identity as a concept and how self/ other identities shape the research relationship. ${ }^{11}$ The research objectives of the project at hand may be much less relevant to informants/participants than the extent to which the researcher is seen as a "decent" person, as one who is genuinely interested in others, and as who can be trusted within the setting. Just as identities and trust cannot be established in fleeting encounters, nor can the understanding that is afforded by developing an intimate familiarity with the setting at hand. Relational patience and perspectival patience are in some central ways bound together. As research relationships develop and trust is enhanced, researchers come to more fully understand the worldviews of others. As members share the egocentric and ethnocentric secrets of the setting, researchers come to more fully appreciate the backstage regions of the setting and the worldviews that make the secrets of the group meaningful to members. ${ }^{12}$

\footnotetext{
${ }^{11}$ See, for example, Shaffir $(1990 ; 1998 ; 1999)$ for discussions of the relationship between identity and reputation in the field.

${ }^{12}$ For example, see Mitchell's (1983) study of climbers and the secrets within the community.
} 
Field research can be time consuming, personally uncomfortable (Wax 1986), involve personal risks (Chomczyński 2018), and be emotively challenging (Kleinman and Copp 1993). It may be convenient in a variety of ways to adopt less personally demanding methodological strategies. By comparison, it certainly does not take much personal commitment to run interviews conducted by others through a qualitative analysis software program. While the product of this work may find a home, our shared enterprise certainly must not be to pursue the minimum publishable unit with as superficial an understanding of the setting at hand as possible.

There are other meaningful challenges, apart from the nature of the activity itself, to patient ethnography. I would be remiss not to note that many of those adopting alternative approaches to classical fieldwork do so while quite mindful of the advantages of the ethnographic tradition. Some may be adopting "methods of necessity" given various anticipated and realized barriers to research. For example, Newmahr and Hannem (2018:3) ask, “How can ethnographers and participant observers continue to do their research, without losing their jobs?" In response they argue for the value of what they term surrogate ethnography, and given their organizing question, the emphasis is not so much on the basis of the merits of the method alone, but on how ethnographers may, as a practical matter, address the excesses of ethics review boards or IRBs.

\section{References}

Adler, Patricia A. and Peter Adler. 2002. “Do University Lawyers and the Police Define Research Values?" Pp. 34-42 in Walking the Tightrope: Ethical Issues for Qualitative Researchers, edited by W. C. van den Hoonaard. Toronto: University of Toronto Press.
Relatedly, the organizational life of universities that previously fostered the ethnographic tradition and the completion of strong fieldwork as a part of the doctoral preparation process has become increasingly challenging. As funding models have changed, restrictions on time to completion imposed on students have influenced research strategies. As graduate student enrolment has become increasingly monetized, departments are organizationally encouraged to increase graduate student teaching/supervisor ratios. Increasing demands for quantity of publication as opposed to quality have encouraged junior faculty members to pragmatically adjust research practice. And as Adler and Adler (2002) note, various forms of university oversight (which they associate with lawyers and policing) have rendered fieldwork in some settings virtually impossible. Taken collectively the challenges to detailed, immersive, and dedicated fieldwork have increased over time.

However, all of this does not exempt social scientists from adopting the research position appropriate for the task at hand. As Blumer (1969:50) writes, "to identify the objects of central concern one must have a body of relevant observations. These necessary observations are rarely those that are yielded by standard research procedure." If researchers are in any way serious about heeding Blumer's (1969:60) injunction to "respect the nature of the empirical world" and organize a methodological position to reflect that respect, then there is not only, as Shaffir (1998) writes, a virtue to patience, but an obligation to it as well.

Athens, Lonnie. 2015a. Dominance and Subjugation in Everyday Life. New Brunswick, NJ: Transaction Publishers.

Athens, Lonnie. 2015b. "Violentization: A Relatively Singular Theory of Violent Crime." Deviant Behavior 36(8):625-639. 
Becker, Howard S. 1963. Outsiders: Studies in the Sociology of Deviance. New York: Free Press.

Becker, Howard S. 2017. Evidence. Chicago: University of Chicago Press.

Berger, Peter and Thomas Luckmann. 1966. The Social Construction of Reality. New York: Anchor.

Blumer, Herbert. 1969. Symbolic Interactionism: Perspective and Method. Englewood Cliffs, NJ: Prentice-Hall.

Brymer, Richard. 1998. "Hanging Out with Good 'Ole Boys, Gangsters and Other Disreputable Characters." Pp. 143-161 in Doing Ethnographic Research: Fieldwork Settings, edited by S. Grills. Thousand Oaks, CA: Sage.

Chomczyński, Piotr. 2018. “Doing Ethnography in a Hostile Environment: The Case of a Mexico Community." Sage Research Methods Cases in Sociology, Academic Level: Postgraduate. Retrieved February 08, 2020 (https://methods.sagepub.com/case/ doing-ethnography-in-hostile-environment-the-case-of-mexico-community).

Colosi, Rachela. 2010. Dirty Dancing? An Ethnography of Lap-Dancing. Abingdon: Willan Publishing.

Couch, Carl J. 1984. "Symbolic Interaction and Generic Sociological Principles." Symbolic Interaction 7(1):1-13.

Dietz, Mary Lou, Robert Prus, and William Shaffir (eds.). 1994. Doing Everyday Life: Ethnography as Human Lived Experience. Toronto: Copp Clark.

Goffman, Erving. 1959. The Presentation of Self in Everyday Life. New York: Anchor.

Goffman, Erving. 1963. Stigma. Englewood Cliffs, NJ: Spectrum.

Grills, Scott. 1989. “Designating Deviance." PhD Dissertation, Department of Sociology, McMaster University, Hamilton, ON, Canada.

Grills, Scott (ed.). 1998. Doing Ethnographic Research: Fieldwork Settings. Newbury Park, CA: Sage.

Grills, Scott. 2018. "Reconsidering Relations in the Field: Attending to Dominance Processes in the Ethnographic Encounter." Pp. 152-160 in The Craft of Qualitative Research, edited by S. W. Kleinknecht, L. K. van den Scott, and C. B. Sanders. Toronto: Canadian Scholars' Press.
Grills, Scott and Robert Prus. 2019. Management Motifs: An Interactionist Approach for the Study of Organizational Interchange. Cham: Springer.

Gubrium, Jaber F. 1991. "Recognizing and Analyzing Local Cultures." Pp. 131-142 in Experiencing Fieldwork: An Inside View of Qualitative Research, edited by W. Shaffir and R. Stebbins. Newbury Park, CA: Sage.

Haas, Jack and William Shaffir. 1987. Becoming Doctors: The Adaption of a Cloak of Competence. Greenwich, CT: JAI.

Helmes-Hayes, Richard and Emily Milne. 2017. “The Institutionalization of Symbolic Interactionism in Canadian Sociology, 1922-1979: Success at What Cost?" Canadian Journal of Sociology 42(2):145-196.

Hillyard, Sam. 2019. "The Rising Salience of the Absent: An Interactionist Analysis." Qualitative Sociology Review 15(2):56-72.

Kleinknecht, Steven W., Lisa-Jo K. van den Scott, and Carrie B. Sanders (eds.). 2018. The Craft of Qualitative Research: A Handbook. Toronto: Canadian Scholars' Press.

Kleinman, Sheryl and Martha A. Copp. 1993. Emotions and Fieldwork. Thousand Oaks, CA: Sage.

Lofland, John. 1976. Doing Social Life: The Qualitative Study of Human Interaction in Natural Settings. New York: John Wiley.

Low, Jacqueline. 2017. "Whither Symbolic Interactionism in Canada?" Canadian Journal of Sociology 42(2):197-202.

Low, Jacqueline and Gary Bowden (eds.). 2013. The Chicago School Diaspora: Epistemology and Substance. Montreal: McGill-Queens University Press.

McLuhan, Arthur and Antony Puddephatt. 2017. “Canadian Symbolic Interactionism on the Global Stage: A Comment on Helmes-Hayes' and Milne's, The Institutionalization of Symbolic Interactionism in Canadian Sociology, 1922-1979." Canadian Journal of Sociology 42(3):325-336.

Mitchell, Richard G., Jr. 1983. Mountain Experience: The Psychology and Sociology of Adventure. Chicago: University of Chicago Press.

Mitchell, Richard G., Jr. 1991. "Secrecy and Disclosure in Fieldwork." Pp. 97-108 in Experiencing Fieldwork: An Inside View of Qualitative Research, edited by W. Shaffir and R. Stebbins. Newbury Park, CA: Sage. 
Newmahr, Staci and Stacey Hannem. 2018. "Surrogate Ethnography: Fieldwork, the Academy, and Resisting the IRB." Journal of Contemporary Ethnography 47(1):3-27.

Pawluch, Dorothy, William Shaffir, and Charlene Miall (eds.). 2005. Doing Ethnography: Studying Everyday Life. Toronto: Canadian Scholars' Press.

Pink, Sarah and Jennie Morgan. 2013. “Short-Term Ethnography: Intense Routes to Knowing." Symbolic Interaction 36(3):351-361.

Prus, Robert. 1996. Symbolic Interaction and Ethnographic Research: Intersubjectivity and the Study of Human Lived Experience. New York: State University of New York Press.

Prus, Robert and C. R. D. Sharper. 1991. Road Hustler: Hustlers, Magic and the Thief Subculture. New York: Kaufman and Greenberg.

Puddephatt, Antony and Arthur McLuhan. 2019. "Generic Social Processes: Reimagining a Conceptual Schema for Grounded Theory in the Contemporary Era." Sociological Focus 2(2):140-155.

Puddephatt, Antony J., William Shaffir, and Steven W. Kleinknecht (eds.). 2009. Ethnographies Revisited: Constructing Theory in the Field. New York: Routledge.

Schütz, Alfred. 1944. "The Stranger: An Essay in Social Psychology." American Journal of Sociology 49(6):499-507.

Schütz, Alfred. 1962. Collected Papers I: The Problem of Social Reality. The Hague: Martinus Nijhoff.

Schütz, Alfred. 1964. Collected Papers II: Studies in Social Theory. The Hague: Martinus Nijhoff.

Scott, Susie. 2018. "A Sociology of Nothing: Understanding the Unmarked." Sociology 52(1):3-19.

Shaffir, William. 1974. Life in a Religious Community: The Lubavitcher Chassidim in Montreal. Toronto: Holt, Rinehart and Winston.

Shaffir, William. 1990. "Managing a Convincing Self-Presentation: Some Personal Reflections on Entering the Field."
Pp. 72-81 in Experiencing Fieldwork: An Inside View of Qualitative Research, edited by W. Shaffir and R. Stebbins. Newbury Park, CA: Sage.

Shaffir, William. 1995. "When Prophecy Is Not Validated: Explaining the Unexpected in a Messianic Campaign." The Jewish Journal of Sociology 37(2):119-136.

Shaffir, William. 1997. "Still Separated from the Mainstream: A Hassidic Community Revisited." Jewish Journal of Sociology 39(1-2):46-62.

Shaffir, William. 1998. "Doing Ethnographic Research in Jewish Orthodox Communities: The Neglected Role of Sociability." Pp. 48-64 in Doing Ethnographic Research: Fieldwork Settings, edited by S. Grills. Thousand Oaks, CA: Sage.

Shaffir, William. 1999. "Doing Ethnography: Reflections on Finding Your Way." Journal of Contemporary Ethnography 28(6):676-686.

Simmel, Georg. 1906. "The Sociology of Secrecy and of Secret Societies." American Journal of Sociology 11(4):441-498.

Spradely, James P. 2000. You Owe Yourself a Drunk: An Ethnography of Urban Nomads. Long Grove, IL: Waveland Press.

Wax, Rosalie. 1986. Doing Fieldwork: Warnings and Advice. Chicago: University of Chicago Press.

Webb, Eugene J. et al. 1999. Unobtrusive Measures. Thousand Oaks, CA: Sage.

Wiseman, Jacqueline P. 1987. “The Development of Generic Concepts in Qualitative Research through Cumulative Application." Qualitative Sociology 10(4):318-338.

Wolf, Daniel. 1991. The Rebels: A Brotherhood of Outlaw Bikers. Toronto: University of Toronto Press.

Zerubavel, Eviatar. 2007. "Generally Speaking: The Logic and Mechanics of Social Pattern Analysis." Sociological Forum 22(2):131-145.

\section{Citation}

Grills, Scott. 2020. “The Virtue of Patience.” Qualitative Sociology Review 16(2):28-39. Retrieved Month, Year (http://www.qualitativesociologyreview.org/ENG/archive_eng.php). DOI: http://dx.doi.org/10.18778/1733-8077.16.2.03 